\title{
Treatment experiences of gonarthrosis by intra-articular infiltration of ozonated autologous blood
}

\author{
Luigi Valdenassi, ${ }^{1,2}$ Marianno Franzini ${ }^{1,3}$ \\ ${ }^{1}$ Facoltà di Medicina e Chirurgia, Università degli studi di Pavia; ${ }^{2}$ Presidente SIOOT - Società Scientifica Ossigeno \\ Ozono Terapia, Gorle (BG); ${ }^{3}$ Presidente SIOOT International, Gorle (BG), Italy
}

\begin{abstract}
Knee arthrosis is a degenerative process with inflammatory characteristics that develops in the articular environment, resulting in irreversible alterations that tend to impair its functionality. In this study, we subjected 136 patients to a new infiltrative therapy by means of autologous ozonated blood. The study yielded positive results on pain symptoms and functional recovery.
\end{abstract}

\section{Introduction}

In orthopedics, knee arthritis is a widespread disease that is second only to vertebral pathology. This illness affects people over 50 and women the most.

Excessive weight, work and/or sports activity over time, and repeated use can produce degenerative changes and lead to muscle and joint imbalances. Such alterations underlie the loss of elasticity and the disappearance of cartilage. Moreover, varus or knee valgus are predisposing conditions.

Articular cartilage is a supporting connective tissue consisting of water, collagen, proteoglycans and chondrocytes. During inflammatory processes, these components are attacked by metalloproteases that initiate cartilage degradation with the involvement of proinflammatory cytokines. ${ }^{1-19}$

Treatment of gonarthrosis can involve surgery or be of a conser-

\footnotetext{
Correspondence: Luigi Valdenassi, Facoltà di Medicina e Chirurgia, Università degli Studi di Pavia, Italy.

E-mail: info@ossigenoozono.it
}

Key words: Autologous blood; ozone; gonarthrosis.

Received for publication: 12 November 2019.

Accepted for publication: 12 November 2019.

${ }^{\circ}$ Copyright: the Author(s), 2019

Licensee PAGEPress, Italy

Ozone Therapy 2019; 4:8697

doi:10.4081/ozone.2019.8697

This article is distributed under the terms of the Creative Commons Attribution Noncommercial License (by-nc 4.0) which permits any noncommercial use, distribution, and reproduction in any medium, provided the original author(s) and source are credited. vative nature. The surgical approach is favoured when the degenerative process compromises fundamental joint functions. The reliability of current surgical techniques provides for a complete functional recovery. Unfortunately, out of approximately 70,000 prosthetic interventions per year in Italy, there are $2 \%$ to $3 \%$ of infections that prove hard to treat due to antibiotic resistance. ${ }^{6}$

The conservative approach is suitable when, despite the discrete relevance of the arthritic process, painful symptoms prevail over functional shortcomings. Non-surgical therapies include the administration of NSAIDs, physiotherapeutic practices, infiltration of viscosupplementary agents or intra-articular infiltrations of growth factors. ${ }^{14,18}$

Our SIOOT centre in Genoa, given the limited interest of a large number of patients in the aforementioned conservative therapies, started to practice a new type of therapeutic approach in April 2015 based on the infiltration of small quantities of autologous blood of patients after their ozonation.

This approaches arises from certain features of stem cells, the articular environment, and ozone metabolism. ${ }^{1-3}$

During in vitro growth, stem cells undergo treatment by Eme Oxygenase 1 (HO-1) and Nitroxidosynthesis (NOS). The by-products of these two enzymes are carbon monoxide (CO) and nitric oxide (NO). These help the same stem cells to withstand oxidative stress and $\mathrm{O}_{2}$ deficiency. Eme Oxygenase 1 also increases the number of endothelial progenitor cells and promotes significant anti-inflammatory activities. ${ }^{4}$

The synovial membrane has phagocytic properties, freeing the articular cavity from catabolites and foreign material, using A synoviocytes and subsinovial macrophages. What is more, it filters substances dissolved in the blood for passage into the synovial fluid, and secretes hyaluronic acid which guarantees the necessary viscosity.

The synovial fluid, a plasma dialysate with $2 \%$ of proteins that in turn are $75 \%$ albumin, develops a cartilage nutrition and joint lubrication function, both of a hydrodynamic nature and via molecular layers. ${ }^{18}$ The first one, paramount during walking, allows the synovial fluid to flow on articular surfaces; the second, when the joint is under load, makes the layer thinner so that the articular heads move by sliding a molecular layer on the other.

Studies of synovial analysis in gonocondropathies show how the inflammatory state alters the permeability of the synovial membrane, increases the concentration of globulins and depolymerises hyaluronic acid, significantly reducing its viscosity.

Among the other functions of elements in the articular environment, it is evident that synovial cells and chondrocytes act as true pluripotent cells, synthesising Collagen, Proteoglycans, Elastin and Glycoproteins. Furthermore, PDGF calls and activates Macrophages, Fibroblasts and TGF $\beta$. In turn, activated Macrophages release PDGF, VDGF and several cytokines such as TGF $\alpha$, IL-1 and TGF $\beta$. 
Macrophage cells play a decisive role in the transition process between inflammation and repair. Growth factors bind themselves to membrane receptors to modulate cell function through specific regenerative processes. We also observe how a normal hyperbaric $\mathrm{O}_{2}$ treatment can result in an eight-fold increase in the number of stem cells circulating in the patient's body. This is due to its activity at the endothelial level which determines the synthesis of NO, underlying the activation of enzymes that in turn favour the release of stem cells. ${ }^{12}$

These observations prompted us to conduct a treatment based on autologous and ozonated blood. In fact, studies on ozone's physiopathology evidenced that this can produce a significant increase in the induction of $\mathrm{NO}$ and $\mathrm{HO}-1$, with relative relapse of the synthesis of mediators, fundamental in counteracting inflammation, the modulation of the immune response, and the production of different growth factors. It seemed appropriate to infiltrate a quantity of ozonated blood in an articular environment considering that the synovial fluid is a plasma dialysate, the circulation of which is hindered by lesions of the condyles and the presence of osteophytes. Moreover, the adhesiveness of condyles on the tibial plates, a typical feature of arthrosic pathology, involves the arterioles and produces ischemic effects; the venous vessels, in which upstream ectatic phenomena occur to generate a space-occupying process; and the same nerve endings, the degeneration of which contribute to the overall discomfort of the entire joint area. Precisely these structures constitute a usual target for the activity of oxygen ozone. Its antineurotoxic and protective activity, in fact, have been known for several years, being thus used to treat pathologies arising from oxygen deficiency and congestive states. Our study examined patients with gonarthrosis assessed by means of the Ahlbach scale (Figures 1-3).

Out of 136 patients enrolled, 94 were females aged between 54 and 70 years, and 42 were males aged between 56 and 72 years.

All patients sought to enroll for primary knee osteoarthritis.

The following inclusion criteria were considered: i) ambulatory patients of both sexes; ii) age above 45 years; iii) one and only one symptomatic knee; iv) suffering from first and second degree gonarthrosis in the Ahlbach scale.

Exclusion criteria: i) gonarthrosis higher than the second degree; ii) symptoms in both knees; iii) deformity in varus or valgus greater than 10 degrees; iv) bending contracture above 15 degrees; v) ligamentous instability or lacerations of the meniscus; vi) having taken NSAIDs within the previous 30 days; vii) intraarticular injections in the previous 12 months; viii) surgery in the previous 6 months; ix) physiotherapy in the previous 30 days.

\section{Materials and Methods}

Patients were recruited according to homogeneous criteria and subjected to our protocol by enrolling in two specialized centres, i.e. Genoa and Bergamo.

The following materials were used: i) ozone generator MultiossigenMedical $95 \mathrm{CPS}$; ii) $5 \mathrm{~mL}$ syringe; iii) $23 \mathrm{G}$ needles (30 $\mathrm{mm} \times 0.3 \mathrm{~mm}$ ); iv) $2.5 \mathrm{~mL}$ of oxygen-ozone mixture at 20 micrograms $/ \mathrm{mL}$ were sampled into the syringe.

Subsequent sampling in the same syringe, of an equivalent quantity $(2.5 \mathrm{~mL})$ of autologous blood.

The syringe was mixed with a slow, circular movement for about 40 seconds to favour blood oxygenation without producing hemolysis and avoiding the addition of anticoagulants. ${ }^{10}$

Infiltration was carried out in different periarticular points of the entire mixture, both with the haematic and gaseous parts, after adequate sterilisation of the area to be treated.
Access for infiltration is from the front, with the patient in supine position with the knee bent at 90 degrees, then identifying the site in the area of least resistance inside the reference point, consisting of a patellar ligament, the lower edge of the lateral femoral condyle, and the upper edge of the tibial plateau.

The insertion of the needle slightly above and parallel to the tibial plateau, slightly inclined medially towards the intercondylar fossa (Figure 4).

The protocol envisages an infiltration per week for five weeks

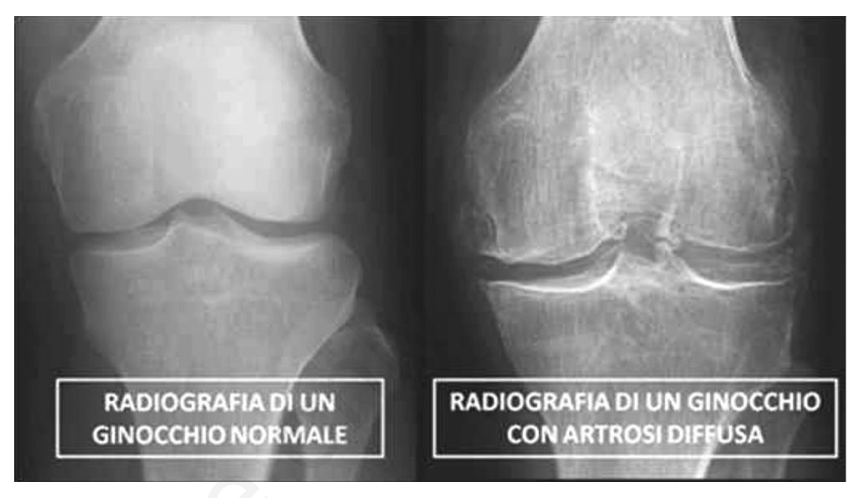

Figure 1. Radiological evidence of a normal and an arthrophic knee.

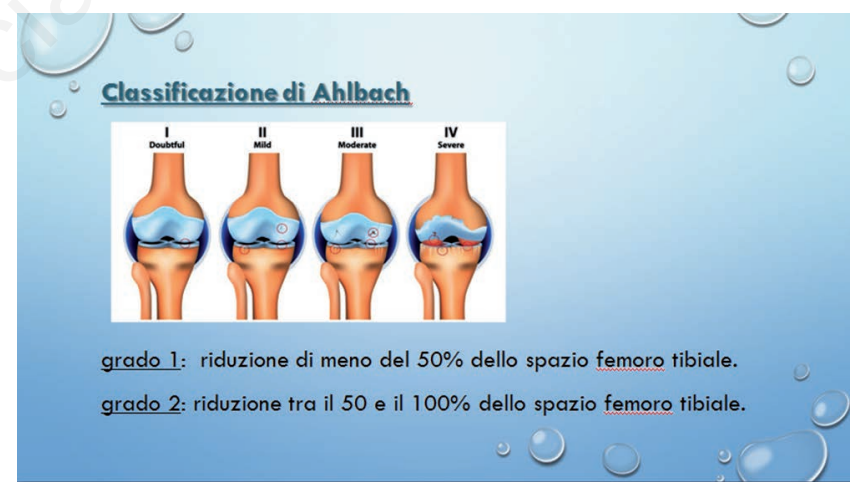

Figure 2. Classification of gonarthrophic pathology according to Ahlbach.

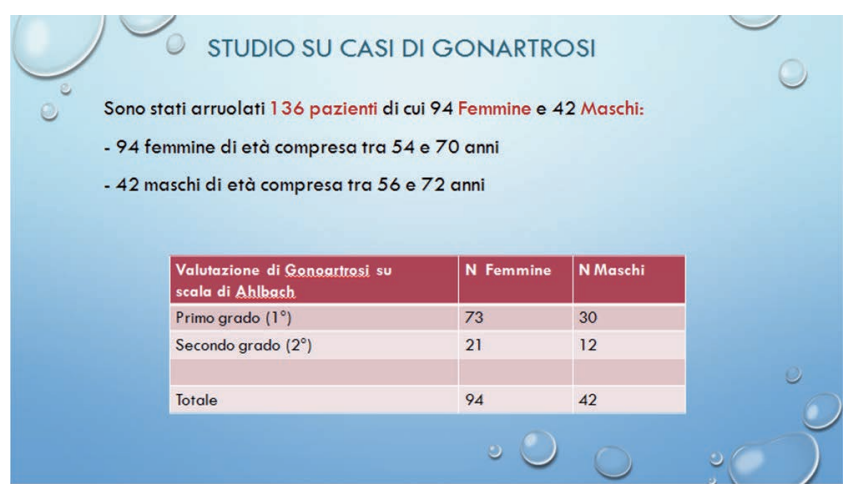

Figure 3. Number and categories of patients enrolled in the trial. 
of $2.5 \mathrm{~mL}$ of autologous blood combined with a mixture of $2.5 \mathrm{~mL}$ of oxygen-ozone at $20 \mathrm{micrograms} / \mathrm{mL}$.

To calculate the Womac Index, the selected sample responded to a specific questionnaire.

The Womac Index evaluates: i) average pain levels; ii) average deficit values; iii) average rigidity values.

The Lequesne Algofunctional Index was also calculated to evaluate: i) pain levels; ii) maximum distance travelled; iii) everyday activities.

\section{Results}

All subjects underwent a specialist examination before and after the treatment. At the same time, they completed the assessment questionnaires to pinpoint any changes concerning pain and joint function before and after treatment.

In all patients treated, both male and female and belonging to groups with first and second degree gonarthrosis on Ahlbach's scale, all parameters assessed via the Womac index saw significant improvement after treatment with $\mathrm{O}_{2} / \mathrm{O}_{3}$ (Figure 5).

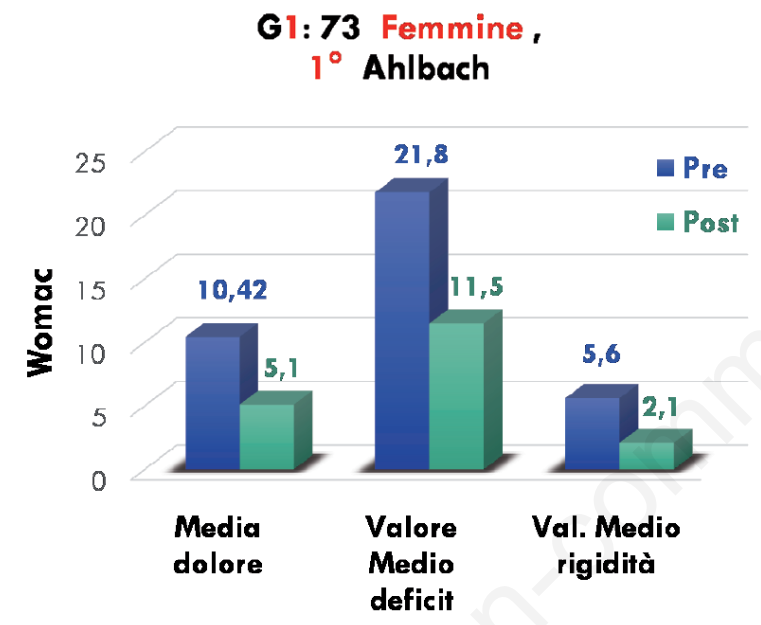

G3: 21 Femmine,
$2^{\circ}$ Ahlbach

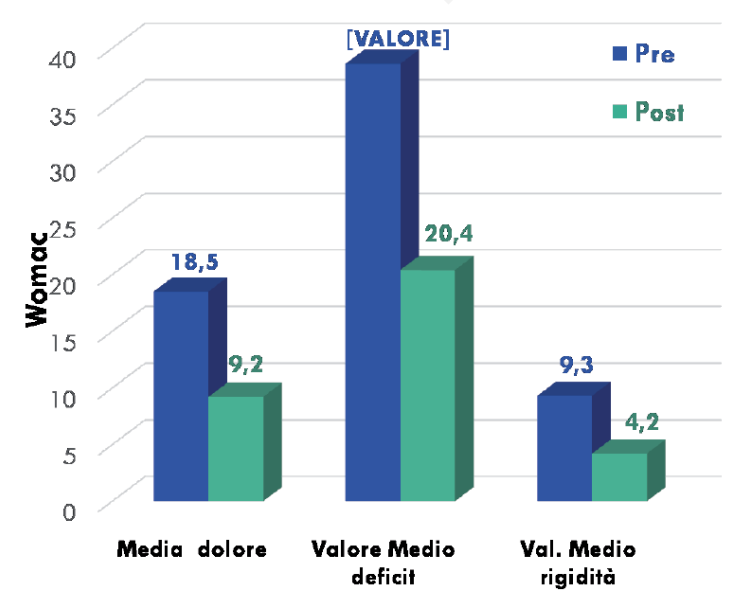

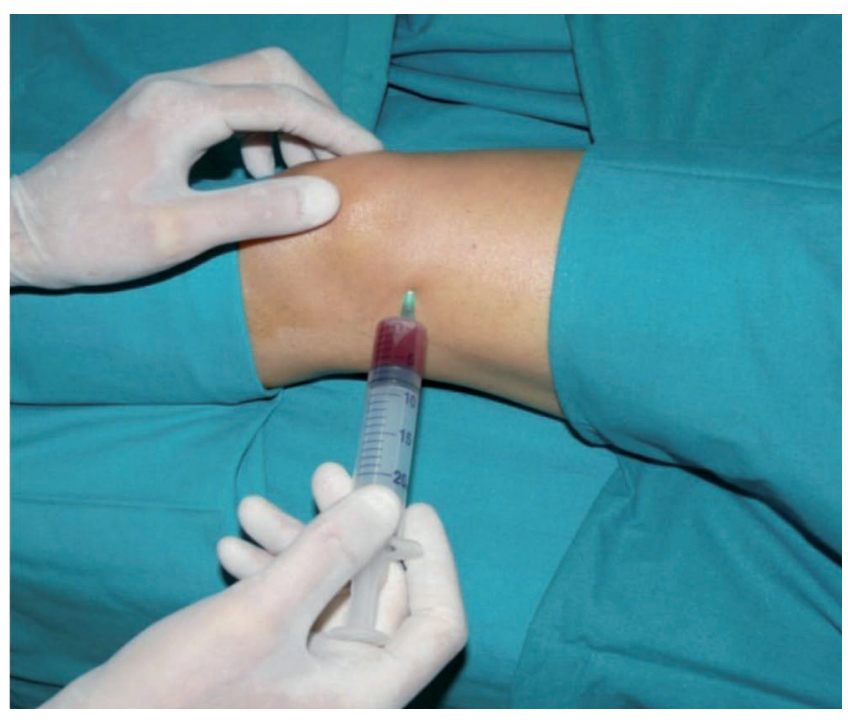

Figure 4. Example of autologous ozonized blood infiltration mode.
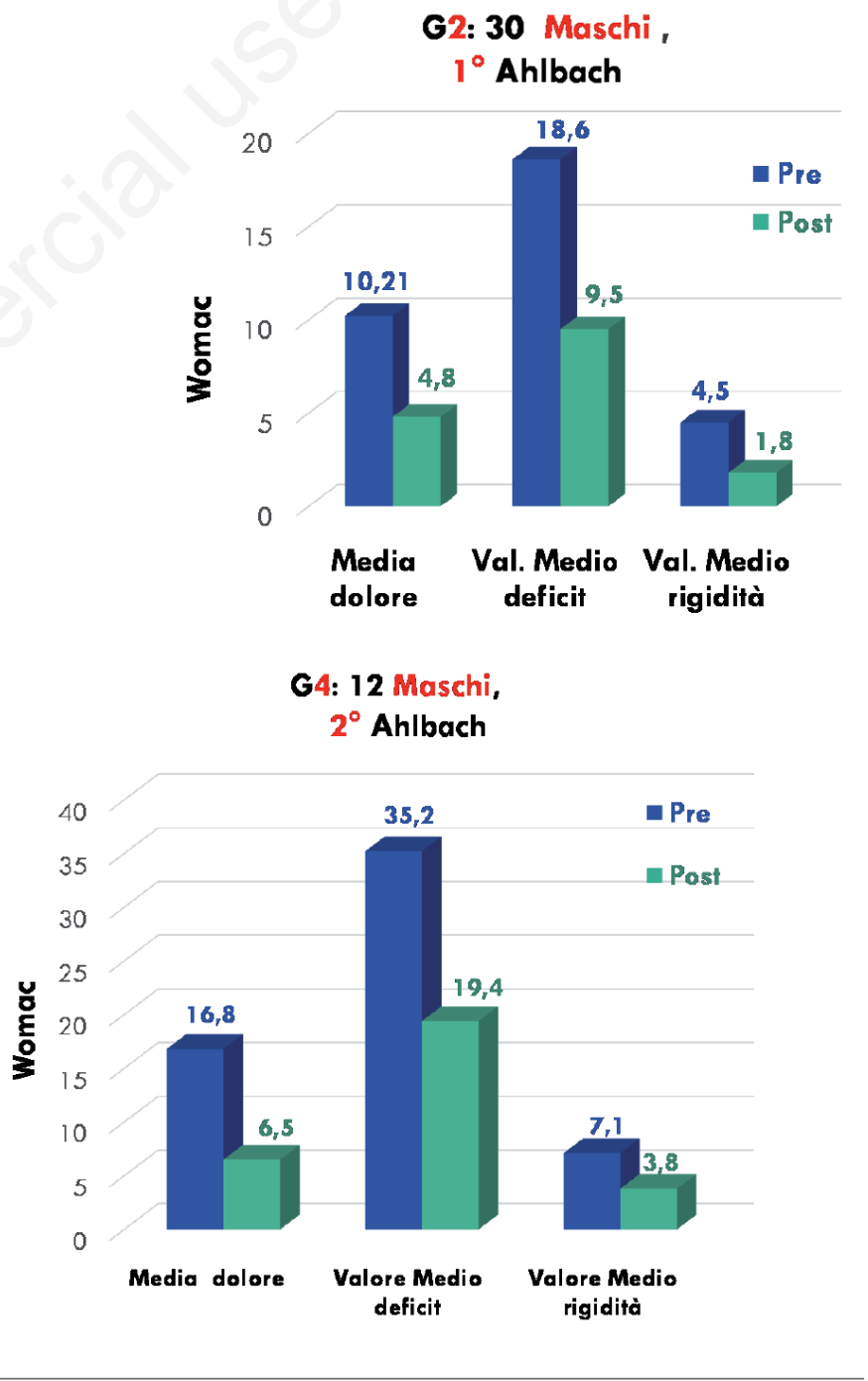

Figure 5. Evaluation of patients according to the Womac Index. 
Likewise via the Lequesne Algofunctional Index (Figure 6).

Patients perceived improvement as the first effective medical intervention after the failure of previous therapies.

\section{Follow-up}

All subjects at the end of the cycle were monitored for the next 11 months.

Efficacy values remained substantially stable throughout the follow-up period on 92 out of 136 patients. 44 patients relapsed to pre-treatment conditions.

Of these 44, 38 were patients of the group with second degree and six with first-degree gonarthrosis; seven did not continue with the trial and the rest were offered the option of joining a new therapeutic cycle, in the evaluation phase.

\section{Discussion}

The degenerative pathology of the knee, due to its etiopathogenetic and pathophysiological features, constitutes an irreversible clinical process that can lead to prosthesisation. For this reason, it is advisable to deal with the problem at the earliest opportunity, as the first symptoms become persistent.

Alternatively, results produced by the infiltration of hyaluronic acid are effective and comparable to those following Plasma infiltration, which should be further investigated given the insufficiently clear responses and their limited duration. ${ }^{16,17}$

Infiltrative therapy using autologous ozonized blood is a new regenerative application that helps delay/avoid surgical reatment.

\section{Conclusions}

Our clinical experience, based on the observation of 136 patients suffering from gonarthrosis and undergoing an infiltrative therapy cycle with autologous ozonized blood, evidenced a significant improvement both in clinical condition - by reducing painful symptoms - and in functional recovery.

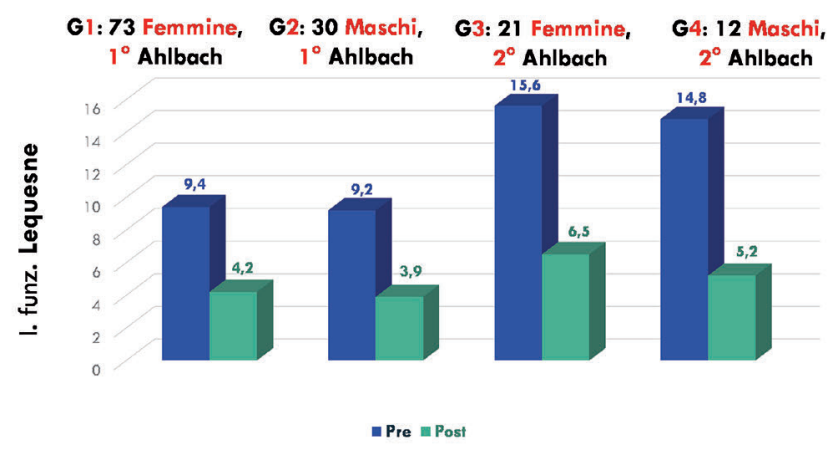

Figure 6. Evaluation of patients according to Lequesne Algofunctional Index.

\section{References}

1. Bocci V, Borrelli E, Travagli V, Zanardi I. The ozone paradox: ozone is a strong oxidant as well as a medical drug. Med Res Rev 2009;29:646-82.

2. Bocci V. Ozone therapy today. Proc. 12th World Congress of the International Ozone Association. Ozone in Medicine. Lille: Tours-Instaprint; 1995. pp 13-27.

3. Stone JR, Yang S. Hydrogen peroxide: a signaling messenger. Antioxid Redox Signal 2006;8:243-70.

4. Stone JR, Collins T. The role of hydrogen peroxide in endothelial proliferative responses. Endothelium 2002;9:2318.

5. Valacchi G, Bocci V. Studies on the biological effects of ozone: 10. Release of factors from ozonated human platelets. Mediat Inflamm 1999;8:205-9.

6. Franzini M, Valdenassi L, Ionita G. First evaluations of oxygen- ozone therapy in antibiotic-resistant infections. Ozone Ther 2016;1:5-7.

7. Inal M, Dokumacioglu A, Ozcelik E, Ucar O. The effects of ozone therapy and coenzyme Q10 combination on oxidative stress markers in healthy subjects. Ir J Med Sci 2011;180: 703-7.

8. Paoloni M, Di Sante L, Cacchio A, et al. Intramuscular oxygen-ozone therapy in the treatment of acute back pain with lumbar disc herniation. Spine 2009;34:1337-44.

9. Verrazzo G, Coppola L, Luongo C, et al. Hyperbaric oxygen, oxygen-ozone therapy, and rheological parameter of blood in patients with peripheral occlusive arterial disease. Undersea Hyperb Med 1995;22:17-22.

10. Valdenassi L, Franzini M, Richelmi P, Berte F. Ossigeno-ozono terapia. Proceedings of the 1st Congress of the SIMFER Section of Ambulatorial Rehabilitation. 2003 Nov 22, Pavia, Italy.

11. Valdenassi L, Franzini M, Simonetti V, Ricevuti G. Oxygenozonetherapy: paradoxical stimulation of ozone. Ozone Therapy 2016;1:5837.

12. Sagai M, Bocci V. Mechanisms of action involved in ozone therapy: is healing induced via a mild oxidative stress? Med Gas Res2011;1:29.

13. American College of Rheumatology (ACR). Ozone gas injections may do the trick for knee osteoarthritis suferers. ScienceDaily. ScienceDaily, 8 November 2015.

14. Zhang H-F, Wang CG, Li H, et al. Intra-articular platelet-rich plasma versus hyaluronic acid in the treatment of knee. Drug Des Devel Ther 2018;12:445-53.

15. Al-Jaziri AA, Mahmoodi SM. Painkilling effect of ozone-oxygen injection on spine and joint osteoarthritis. Saudi Med J 2008;29:553-7.

16. Giombini A, Menotti F, Di Cesare A, et al. Comparison between intrarticular injection of hyaluronic acid, oxygen ozone, and the combination of both in the treatment of knee osteoarthrosis. J Biol Regul Homeost Agents 2016;30:621-5.

17. Duymus TM, Mutlu S, Dernek B, et al. Choice of intra-articular injection in treatment of knee osteoarthritis: platelet-rich plasma, hyaluronic acid or ozone options. Knee Surg Sports Traumatol Arthrosc 2017;25:485-92.

18. Alshami AM. Knee osteoarthritis related pain: a narrative review of diagnosis and treatment. Int J Health Sci (Qassim) 2014;8:85-104.

19. Bruyère $\mathrm{O}$, Cooper $\mathrm{C}$, Arden $\mathrm{N}$, et al. Can we identify patients with high risk of osteoarthritis progression who will respond to treatment? a focus on epidemiology and phenotype of osteoarthritis. Drugs Aging 2015;32:179-87. 